\title{
As revistas de ano de Artur Azevedo: espaços de beterogeneidade cultural
}

Alberto Tibaji"

O objetivo deste artigo é mostrar que as revistas de ano de Artur Azevedo eram um espaço em que conviviam estratos culturais bastante heterogêneos. Nesse sentido, iniciaremos com um paralelo entre as revistas de ano escritas por Artur Azevedo e as mudanças por que passava o espaço urbano carioca no fim do século XIX e início do século XX. Com isso esperamos contribuir para uma compreensão mais aprofundada do referido período e para uma reflexão sobre a riqueza das relações culturais no teatro do fim do século XIX.

\section{As transformações do espaço urbano}

As revistas de ano do autor maranhense estiveram presentes na cena brasileira durante o período em que se verificou uma tentativa de modernização do país, culminando justamente com o que chamamos de Belle Époque e com as reformas empreendidas pelo prefeito Pereira Passos. Sua primeira revista chamou-se O Rio de Janeiro em 1877. A peça foi escrita em parceria com o autor português Tomás Lino d'Assunção e representada em 1878, no Teatro São Luís, no Rio de Janeiro. Seguiram-se mais dezoito revistas de ano, tendo a última sido escrita e publicada em 1908.

As reformas de Pereira Passos foram implementadas no período de 1903 a 1906, porém, o movimento de modernização, que culminou no famoso Bota-Abaixo, começara bem antes. Já em 1874 o mesmo Pereira Passos, enquanto engenheiro do Ministério do Império, elaborou um primeiro plano de reforma que enfrentou críticas até mesmo por parte do Imperador e não foi levado adiante. Desde então até o fim do século XIX, houve apenas algumas interferências pontuais na cidade, destacando-se a reforma do Campo de Santana (NEEDELL, 1993, p. 52-55).

Geralmente a reforma realizada por Pereira Passos é vista pelo viés político, acentuando-se seu desrespeito pelas populações de baixo nível econômico. Inicialmente, a idéia do prefeito era aproveitar ruas já existentes, reformando-as e alargando-as, abrindo desse modo um corredor no sentido norte-sul da cidade. Foram Lauro Müller e Paulo de Frontin que convenceram-no da necessidade de traçar uma linha reta, destruindo o que fosse necessário e conveniente para atingir seu objetivo. Com isso, muitas casas populares foram destruídas e os habitantes obrigados a mudar para bairros mais distantes, como a Cidade Nova. Instalava-se uma nova geografia: a zona norte tornou-se sinônimo de camadas populares e as zonas sul e centro tornaram-se sinônimo de elite. 
Alegando garantir melhores condições de vida à população mais pobre, o governo desapropria e põe abaixo grande parte dos prédios e casarões das ruas centrais da cidade. Desalojadas do centro, as camadas populares são obrigadas a se deslocarem para os subúrbios e favelas da periferia (VELLOSO, 1988, p. 11).

O nosso "Haussmann tropical", como foi chamado, realizou uma verdadeira "higienização" biológica e social na cidade do Rio de Janeiro, trabalhando com Oswaldo Cruz e os já citados Müller e Frontin.

O símbolo do processo de modernização carioca era a Avenida Central que atravessava grande parte da cidade velha e unia-se ao sul a outra avenida de grande importância social para o período: a Beira-mar. Aquela avenida tinha sido planejada inclusive no que diz respeito às fachadas das edificações: a Biblioteca Nacional, o Museu Nacional de Belas Artes, o Teatro Municipal e o já demolido Palácio Monroe.

A avenida havia sido planejada com objetivos que ultrapassavam em muito as necessidades estritamente viárias - ela foi concebida como uma proclamação. Quando, em 1910, seus edifícios ficaram prontos, e o conceito da avenida se completou, uma magnífica paisagem urbana passou a embelezar o Rio. A Capital Federal possuía agora um bulevar verdadeiramente "civilizado" - duas muralhas paralelas de edifícios que refletiam o máximo de bom gosto existente - e um monumento ao progresso do país. (...) As fachadas e as forças que elas representavam e incentivavam haviam sido tão cuidadosamente planejadas quanto o traçado da Avenida (NEEDELL, 1993, p. 6061).

Um dos valores fundamentais da modernização é a idéia de circulação, daí as ferrovias, as estradas, o automóvel, a eletricidade, o cinema, o rádio: "o princípio de “circulação' é um elemento estruturante da modernidade que emerge no século XIX" (ORTIZ, 1991, p. 195). Se durante o referido século a construção de um teatro era saudada como símbolo de civilização ${ }^{1}$, agora, no início do século XX, o símbolo da civilidade é uma rua.

Pereira Passos, contudo, fez muito mais. Pavimentou ruas, construiu calçadas e asfaltou estradas, abriu o túnel do Leme (o segundo a ligar o subúrbio distante de Copacabana aos subúrbios mais próximos da Cidade Velha), iniciou a Avenida Atlântica, criou a avenida ligando os subúrbios do Flamengo e Botafogo, melhorou uma série de outras $\operatorname{ruas}^{2}$ (NEEDELL, 1993, p. 57).

Pode-se perceber, contudo, uma diferença entre a cidade ideal, concebida pela equipe de Rodrigues Alves e Pereira Passos, e a cidade real, aquela que é ocupada pela população. A Avenida Central, com suas fachadas elegantes e ecléticas, vai sendo ocupada pela população em geral e não apenas pela elite local. A avenida é lugar para circulação de pessoas, de mercadorias e de idéias.

Ou seja, se por um lado as reformas levadas a cabo por Pereira Passos criaram ou reforçaram uma hierarquia espacial dentro da cidade, com bairros nobres afastados de bairros populares, por outro lado criaram as condições para que a população de baixa renda pudesse circular pelas mesmas avenidas que a população mais abastada, cada uma a seu modo. 
Indiferentes aos apelos $\mathrm{da}$ ordem, os grupos carnavalescos rompiam e rasgavam as fronteiras urbanas. Engalanados à sua moda, queriam o centro da cidade, insistiam em cruzar a Avenida Central ou as ruas elegantes, tomavam conta dos bondes e atravessavam a capital, subvertendo com sua simples presença as regras da civilidade e do bom-tom para os que desfrutavam os encantos da belle époque (CUNHA, 2001, p. 174).

Entretanto, não era apenas em ocasiões festivas excepcionais que as camadas populares ocupavam a Avenida. Vejamos o que disse um cronista na revista Fon Fon em junho de 1909:

a população do Rio que, na sua quase unanimidade, felizmente ama o asseio e a compostura, espera ansiosa pela terminação desse hábito selvagem e abjeto que nos impunham as sovaqueiras suadas e apenas defendidas por uma simples camisa de meia rota e enojante de suja, pelo nariz do próximo e do vexame de uma súcia de cafajestes em pés no chão (sob o pretexto hipócrita de pobreza quando o calçado está hoje a 5 \$ o par e há tamancos por todos os preços) pelas ruas mais centrais e limpas de uma grande cidade... $\mathrm{Na}$ Europa ninguém, absolutamente ninguém, tem a insolência e o despudor de vir para as ruas de Paris, Berlim, de Roma, de Lisboa, etc., em pés no chão e desavergonhadamente em mangas de camisa (Citado em SEVCENKO, 1999, p. 34).

Ou então o interessante comentário de Olavo Bilac, publicado na Revista Kosmos em 1906, inconformado com o fato de os contingentes "bárbaros" da população invadirem a "civilização":

Num dos últimos domingos vi passar pela Avenida Central um carroção atulhado de romeiros da Penha: e naquele amplo boulevard esplêndido, sobre o asfalto polido, contra a fachada rica dos prédios altos, contra as carruagens e carros que desfilavam, o encontro do velho veículo, em que os devotos bêbedos urravam, me deu a impressão de um monstruoso anacronismo: era a ressurreição da barbárie - era uma idade selvagem que voltava, como uma alma do outro mundo, vindo perturbar e envergonhar a vida da cidade civilizada... Ainda se a orgia desbragada se confinasse ao arraial da Penha! Mas não! Acabada a festa, a multidão transborda como uma enxurrada vitoriosa para o centro da urbs... (Bilac citado em SEVCENKO, 1999, p. 69.).

\section{A noção de beterogeneidade}

Nossa análise do caráter de heterogeneidade da obra de Artur Azevedo inspira-se nas reflexões do intelectual peruano Antonio Cornejo Polar. Em seu livro $O$ condor voa, encontramos três capítulos dedicados ao tema da heterogeneidade. Cornejo Polar analisa, dentre outros tipos de literatura, o wanka peruano e a relação insolúvel entre cultura quéchua e cultura hispânica na referida manifestação, abrindo um vasto horizonte para a compreensão de obras teatrais a partir de sua heterogeneidade. $\mathrm{O}$ autor parte do conflito entre cultura oral e cultura escrita num episódio que marcou a história do Peru: o encontro em Cajamarca dos incas com os espanhóis. Cornejo 
Polar transcreve tanto alguns testemunhos, hispânicos evidentemente, quanto outras leituras do episódio, incluindo, então, a letra indígena. O que o autor acentua é a impossibilidade do diálogo entre as duas culturas. Esse abismo, no entanto, não é característica apenas do momento em que os colonizadores empreenderam seus ataques aos povos autóctones:

esse episódio, como já afirmamos, tem algo como uma ubiqüidade temporal: está lá e no tempo passado, mas também aqui e no tempo presente, carregando-se sempre de novas experiências e de novos sentidos, e mesmo gestando, em alguns casos, conteúdos que falam de um futuro que corrigirá a desordem cósmica iniciada com a conquista (CORNEJO POLAR, 2000, p. 269).

A partir dessa noção, tentamos compreender o texto e a cena azevedianos, sem tentar reduzi-los às idéias de harmonia ou de sincretismo cultural tão presentes no Brasil e na América Latina: Cornejo Polar, ao desmontar o discurso da harmonia imposta entre outras pela ideologia da mestiçagem -, leva-nos a captar as tensões internas e contraditórias da América Latina (ORTIZ, 2005, p. 160).

\section{A música no teatro de revista de Artur Azevedo}

A revista de ano era um tipo de texto/espetáculo teatral bastante específico e que vigorou também durante um período bastante determinado em nossa história. Espetáculo fundamentalmente musicado e cômico, a revista era construída a partir de fatos e personalidades de destaque do ano anterior ao da representação da peça. Ou seja, nos primeiros meses de 1889, a cena revisteira re-apresentava o que de mais interessante ocorrera em 1888. No caso, a abolição e seus festejos seriam presença indispensável na peça. É necessário sublinhar que não se tratava de um panorama de cenas justapostas, mas de uma recriação ficcional de elementos históricos, quer dizer, eram escolhidos eventos ou figuras públicas que colaborassem para o desenvolvimento da intriga dramática. Cada autor, ou dupla de autores - o que era bastante comum na época -, dava, portanto, sua visão do ano transcorrido.

Dramaturgicamente, o gênero teatral em questão equilibrava-se entre um fio condutor e cenas episódicas, que podiam ser alteradas, ou substituídas, durante a temporada da peça.

Foram muitos os autores que escreveram revistas de ano no final do século XIX. Todavia, a pesquisa em artes cênicas apenas muito recentemente vem se dedicando ao estudo desse gênero teatral, de grande popularidade e com grande quantidade de obras representadas, porém poucas publicadas. Os trabalhos existentes abordam unicamente a obra de Artur Azevedo e a da parceria Cardoso de Menezes e Carlos Bittencourt ${ }^{4}$. Todos os outros estudos são de caráter geral ou panorâmico sobre o tema, daí limitarmo-nos unicamente ao comentário da obra de Artur Azevedo.

O que vamos destacar aqui é o princípio da heterogeneidade, presente nas

obras. Uma característica própria ao gênero vai dar suporte a esse princípio: o fio 
narrativo das revistas de ano é em geral uma visita ou uma perseguição dentro da cidade que será passada em revista, o que significa que os personagens da espinha dorsal deverão circular pela cidade, deparando-se com aspectos diversos da mesma. $\mathrm{Na}$ revista de ano $\mathrm{O}$ mandarim, a primeira escrita pela parceria Artur Azevedo e Moreira Sampaio (1985a) e representada a partir de janeiro de 1884, aparecem em cena: um casal chinês (o mandarim Tchin Tchan Fó e sua esposa Peky), uma cocote, um bacharel, um poeta, um capoeira, o Barão de Caiapó e um mestre-escola da roça, além de vários personagens alegóricos, tais como diferentes jornais e teatros e a febre amarela. Estão, portanto, representados em cena diversos estratos sociais.

Porém, um dos elementos que mais chama a atenção é a música. $O$ espaço musical da revista de ano é de enorme heterogeneidade. Veja-se, por exemplo, na peça O bilontra de Artur Azevedo e Moreira Sampaio (1985b). Em anúncio publicado na Gazeta de Notícias em fevereiro de 1886 são listados 53 números musicais, dentre os quais destacamos: uma paródia a La donna è mobile, uma canção espanhola, uma música da opereta francesa $A$ mascote, a música do bailado das Horas da Gioconda de Ponchielli, um jongo, o lundu do Teatro Recreio da Cidade Nova, uma charanga, um galope, um coro de música sacra, um tango brasileiro e a Marselhesa. Portanto, além de termos um espectro musical amplo em relação à nacionalidade das músicas, temos uma heterogeneidade de estratos culturais, pois há músicas de ópera que eram, em teoria, destinadas a um público mais erudito (Rigoletto e Gioconda) e a charanga, o jongo e o lundu, destinados a um público de poucos recursos econômicos.

O lundu, cuja origem está intimamente ligada aos batuques e danças de origem africana, foi sendo paulatinamente reelaborado por músicos eruditos e aos poucos deu origem a um tipo específico de lundu, que além de valorizar os movimentos sensuais da dança, valorizava também a letra da música, freqüentemente cômica. Segundo Tinhorão, os músicos de teatro "viam no casamento de um texto engraçado com a malícia da dança uma boa atração para o público de brancos amantes das emoções eróticas" (TINHORÃO, 1974, p. 47).

O jongo é um tipo de música também de origem africana ainda dançada, tocada e cantada atualmente em algumas comunidades fluminenses. Em O bilontra, o jongo de Gomes Cardim é cantado por um coro de pretos sexagenários, mas causa certo alarme no público mais refinado, chegando um folhetinista a defini-lo como uma "excrescência" ( $A$ vanguarda, Teatros e salões - O Bilontra, 30 jan. 1886). Já o crítico P. Talma, em seu comentário publicado em $A$ Semana, afirma: "a música é em geral bem escolhida e há trechos originais do maestro Gomes Cardim que muito honram o seu autor. Excetuaremos deste número o jongo dos sexagenários, encaixado a martelo na revista, como muito bem diz o Sr. Joaquim Nunes" (A Semana, Teatros, $\mathrm{O}$ Bilontra, 6 fev. 1886). Curiosamente, este jongo, cuja letra não foi publicada junto com o texto da peça, foi um dos poucos números musicais cuja partitura foi publicada 6 . A partir da partitura podemos imaginar o desconforto que a letra da música podia causar numa sociedade que ainda funcionava dentro do regime escravocrata: "par'os blanco que dia sinistro aquele que os negro chegar a ministro" (GOMES CARDIM, s.d., p. 3) 
Outro exemplo bastante expressivo dessa heterogeneidade cultural presente nas revistas de ano de Artur Azevedo aparece na peça Mercúrio. Ainda antes do término do quadro dos teatros há uma espécie de "duelo" entre o Capadócio, desempenhado por Xisto Bahia, e Cupido, feito pela atriz Cinira Polônio. O Capadócio, que tenta ouvir algumas cançonetas francesas num café-concerto, acaba entrando numa grande confusão e faz pouco caso das cançonetas. Cupido desafia-o, cantando uma. O Capadócio canta em seguida uma modinha brasileira, acompanhando-se ao violão:

CUPIDO: Digo e redigo. Ouça lá esta... veja se em todo o [seu] repertório há coisa que se compare. (Canta uma cançoneta francesa).

O CAPADÓCIO: Agora eu! Não tenho medo da comparação. Ouça, e diga se isto não vale mais do que o seu trá-lá-lá. (Canta uma modinha brasileira, acompanhandose ao violão) (AZEVEDO, 1987a, p. 233).

É exatamente este o momento de "movência" mais importante do espetáculo: tanto as cançonetas, cantadas por Cinira, quanto as modinhas, cantadas por Xisto Bahia, podem ser substituídas por outras, o que serve de atrativo para o público9.

Além disso, não se pode esquecer que todo esse leque de músicas era interpretado por uma orquestra constituída por instrumentos da cultura erudita: violinos, baixos, flautas, clarineta etc. Imagine-se, por exemplo, a cena de $A$ fantasia em que a atriz italiana Amélia Lopiccolo interpreta um mulatinho "petulante", com seu falar tipificado e canta maliciosas coplas, ao som de violinos, tendo como cenário "uma sala na Cidade Nova”, um bairro que na época já era habitado por camadas mais economicamente desfavorecidas, por negros e mulatos. Ou então, a mesma italiana Lopiccolo cantando um lundu, ao som de uma orquestra de violinos e flautas, em meio ao Parnaso, na mesma revista.

É importante observar que essa heterogeneidade também pode ser percebida em peças escritas pelo maranhense e que pertencem a outros gêneros. Destacamos aqui apenas o trabalho que desenvolvemos com as partituras de $A$ capital federal, pois podemos encontrar nela características musicais semelhantes às das revistas de ano. A peça apresenta coplas, lundus, valsas, tango e rondós dentre outros gêneros.

\section{Outros exemplos de beterogeneidade}

Não podemos deixar de comentar a competência de Artur Azevedo para coadunar num texto dramático elementos que, em princípio, deveriam pertencer a diferentes estéticas. Voltamos aqui novamente ao exemplo de $A$ fantasia. Para essa revista de ano, representada durante o mês de agosto de 1896, Artur Azevedo criou, por exemplo, cenas em versos para os habitantes do Olimpo e uma cena em que parodia versos de dois poetas extremamente conhecidos à época (Casimiro de Abreu e Tomás Ribeiro, este último português), parodiando também, nessa mesma cena, os melodramas que agradavam a um público mais amplo. Se nesses momentos revelam- 
se os dotes artísticos do comediógrafo maranhense, em outros revela-se sua preocupação em manter em suas peças elementos que podem conquistar o grande público: lundus, caricaturas vivas e sátiras.

Essa heterogeneidade possibilitou o aparecimento de algumas notas na imprensa, como a que segue: "apesar do seu feitio literário e da sua decência e compostura, a Fantasia encontra muitos apreciadores num público viciado" (A Notícia, Teatros, A fantasia, 22 ago. 1896).

Finalmente, acreditamos que o momento que melhor simboliza esse caráter heterogêneo está em O tribofe. Um dos fios condutores da peça é a chegada de uma família de roceiros ao Rio de Janeiro, então capital federal. Aos poucos, alguns integrantes da família são contaminados pelo "micróbio da pândega" e perdem-se na cidade. A mucama, chamada Benvinda, desgarra-se do núcleo familiar e é aliciada por um homem que tenta transformá-la em prostituta de luxo. Na cena 4 , quadro 5 , ato II, Eusébio, chefe da família roceira e portanto seu patrão anterior, encontra Benvinda já se comportando como prostituta:

Eusébio leva-as [Quinota e Dona Fortunata] até o bastidor, e voltando, vê pelas costas Benvinda, que entra pelo primeiro plano muito bem trajada, mas com certa exageração ridícula: Olé! Que tentação! (Seguindo Benvinda.) Psiu! Ó dona!... Dona!... (Benvinda volta-se.) Benvinda!...

Benvinda: Ob!... (Assestando uma marquise.) Viva! Como tem passado?...

Eusébio: A mulata de luneta, minha Nossa Senhora!... Este mundo tá perdido!...

(AZEVEDO, 1986, p. 94-95).

Luneta aqui é, certamente, sinônimo de instrumento com pequena haste, usado para enxergar melhor ${ }^{10}$. A importância desse momento na peça pode ser confirmada pelo título do quadro: a mulata de luneta (cf. anúncio na Gazeta de Notícias, 16 jun. 1892).

\section{Considerações finais}

A combinação de elementos díspares, a mulata - sinônimo de mestiçagem, luxúria e cultura das camadas desfavorecidas - e a luneta - sinônimo de intelectualidade, clareza e erudição - , causa tamanho espanto no fazendeiro, que ele chega a exclamar com seu sotaque roceiro: “este mundo tá perdido!". Perdido porque não se respeitam mais as fronteiras e limites, que antes eram tão demarcados: lunetas para senhoras de respeito e requebros para a mulata; música erudita para um lado e música popular para o outro; elaboração dramatúrgica para os gêneros superiores, incluindo-se aí a alta comédia, e recurso às soluções fáceis para os gêneros inferiores ${ }^{11}$. $\mathrm{O}$ espanto de Eusébio é também o espanto dos literatos diante das revistas de Artur Azevedo, verdadeiras mulatas de lunetas, reunindo, numa única obra, a luxúria, o intelecto, o culto, o tradicional, o mestiço, a exatidão e a improvisação. Como compreender que um autor do porte de Artur Azevedo, que seria, em 1897, um dos 
fundadores da Academia Brasileira de Letras, pudesse não apenas insistir em escrever revistas, mas defender a estética desse teatro heterogêneo, que une a arte ao comércio?

Ocorre com as revistas de ano de Artur Azevedo algo semelhante com a Avenida Central. A diferença está em que a Avenida foi projetada para ser um espaço para a elite civilizada, enquanto que a revista de ano do nosso comediógrafo não tinha essa intenção. Porém, nos dois espaços transitam manifestações que pertencem a estratos culturais bastante heterogêneos, cada um mantendo seus valores.

Pode-se estudar a obra de Artur Azevedo a partir de muitas perspectivas. A que nos parece mais fecunda, no entanto, é a que considera esse nosso homem de teatro como alguém que viveu intensamente as contradições da cultura brasileira. Não podemos terminar nossa breve reflexão sem citar, portanto, um esclarecedor trecho de Cornejo Polar que nos tem guiado nessa trajetória:

Como pode o pensamento crítico-histórico enfrentar uma literatura que desdobra com tamanha evidência suas radicais contradições, sua tenaz e englobadora heterogeneidade?

Por certo, não fingindo unidade e coerência onde o que existe é claramente contraste e ruptura, mas tampouco negando a nação em favor de um desmembrado pluralismo étnico; ao contrário, sob o aval dessa constatação do múltiplo, construindo um objeto que só tem sentido em sua contradição: em outras palavras, uma literatura que somente se reconhece em sua radical e insolúvel heterogeneidade, como construção de vários sujeitos social e etnicamente dissímiles e confrontados, de racionalidades e imaginários distintos e inclusive incompatíveis, de linguagens várias e díspares em sua mesma base material, e tudo no interior de uma história densa, em cuja espessura acumulamse e desordenam-se vários tempos e muitas memórias (CORNEJO POLAR, 2000, p. 296).

Notas

"Alberto Ferreira da Rocha Junior.

${ }^{1}$ Regina Horta Duarte, em seu livro sobre teatro e circo em Minas Gerais no século XIX, afirma: "saudava-se a construção de edifícios específicos para o funcionamento de teatros como um importante indicador do grau de civilização das localidades” (DUARTE, 1995, p. 120).

${ }^{2}$ A enumeração é bastante longa e o autor cita também o embelezamento de praças e a proibição de costumes considerados inadequados para uma cidade moderna e civilizada.

${ }^{3}$ Artur Azevedo escreveu seis revistas em parceria com Moreira Sampaio e outras em parceria com Lino d'Assunção, França Júnior, Aluísio Azevedo e Gastão Bousquet. Para um estudo mais aprofundado de algumas revistas de ano de Artur Azevedo, conferir nossa Tese de Doutorado (ROCHA JUNIOR, 2002). ${ }^{4}$ Essa dupla atuou nas décadas de 1910 e 1920, na Companhia de revistas e burletas do Teatro São José, do empresário Pascoal Segreto. Para uma reflexão sobre essa dupla, conferir CHIARADIA, 1997.

${ }^{5}$ Para uma visão geral do tema, conferir VENEZIANO, 1991 e VENEZIANO, 1996.

${ }^{6}$ Temos notícia da publicação apenas de mais um número musical de O bilontra: o Tango Recreio da Cidade Nova, mais conhecido como “Ataca, Felipe!”. Deste número musical localizamos duas publicações diferentes. Todas as partituras, inclusive a do jongo, fazem parte do acervo da Fundação Biblioteca Nacional. 
${ }^{7}$ A letra da música certamente refere-se à Lei no 3.270, promulgada em setembro de 1885, mais conhecida como Lei dos Sexagenários: "Nosso gente já s'tá livre só trabalha si quizé/Si siô! toca zumba zumba zumba toca zumba zumba zumba!”. É preciso também lembrar que Artur Azevedo foi um abolicionista ativo.

${ }^{8}$ A noção de "movência" é descrita em Zumthor (1993). Usamo-la aqui da mesma forma que Chiaradia (1997) para compreender um texto que exige sua performance e, em conseqüência, transforma-se.

${ }^{9}$ Os anúncios, em geral, dizem que haverá novas modinhas no espetáculo. Quanto às cançonetas, algumas vezes constam seus títulos: Trois, rue du paon e La demoiselle de Commercy.

${ }^{10}$ Cf. nota 61, da edição que utilizamos, p. 199-200.

${ }^{11} \mathrm{~A}$ importância do respeito às fronteiras, limites e hierarquias está presente também nas lutas travadas para civilizar o carnaval nessa mesma época. Cf. Cunha, 2001, pp. 58 e 84.

\section{Bibliografia}

AZEVEDO, Artur e MOREIRA SAMPAIO. “O mandarim", in: O teatro de Artur Azevedo, Rio de Janeiro: INACEN, v. 2, 1985a. pp. 213-276.

AZEVEDO, Artur, "O bilontra”, in: O teatro de Artur Azevedo, Rio de Janeiro: INACEN, v. 2, 1985b. pp.289-370.

, O tribofe, Rio de Janeiro: Nova Fronteira; Fundação Casa de Rui Barbosa, 1986.

, "Mercúrio", in: O teatro de Artur Azevedo, Rio de Janeiro: INACEN, v. 3, 1987a. pp.161-238.

, "A fantasia”, in: O teatro de Artur Azevedo, Rio de Janeiro: INACEN, v. 4, 1987b. pp.227-312.

CHIARADIA, Maria Filomena Vilela, A companhia de revistas e burletas do Teatro São José: a meninados-olhos de Paschoal Segreto, Rio de Janeiro, 1997. Dissertação (Mestrado em Teatro) Escola de Teatro da UNI-RIO.

CORNEJO POLAR, Antonio, O condor voa. Literatura e cultura latino-americanas, Belo Horizonte: Ed. UFMG, 2000.

CUNHA, Maria Clementina Pereira, Ecos da folia: uma história social do carnaval carioca entre $1880 \mathrm{e}$ 1920, São Paulo: Companhia das Letras, 2001.

DUARTE, Regina Horta, Noites circenses: espetáculos de circo e teatro em Minas Gerais no século XIX, Campinas, SP: Ed. UNICAMP, 1995.

GOMES CARDIM, O bilontra. Dança dos negros. Jongo do $3^{\circ}$ acto, S.l.: s.n., s.d. 1 partitura (3 p.). Piano e canto.

NEEDELL, Jeffrey D., Belle époque tropical: sociedade e cultura de elite no Rio de Janeiro na virada do século, São Paulo: Companhia das Letras, 1993.

ORTIZ, Graciela Raquel, "Heterogeneidade” in: FIGUEIREDO, Eurídice (org.), Conceitos de literatura e cultura, Juiz de Fora: Ed. UFJF, 2005. 143-162.

ORTIZ, Renato, Cultura e modernidade. A França no século XIX, São Paulo: Brasiliense, 1991.

ROCHA JUNIOR, Alberto Ferreira da, Teatro brasileiro de revista: de Artur Azevedo a São João del-Rei, São Paulo. 2002. Tese (Doutorado em Artes) USP.

SEVCENKO, Nicolau, Literatura como missão: tensões e criação cultural na Primeira República, São Paulo: Brasiliense, 1999.

TINHORÃO, José Ramos, Pequena história da música popular (da modinha à canção de protesto), Petrópolis: Vozes, 1974.

VELLOSO, Mônica Pimenta, As tradiçôes populares na Belle Époque carioca, Rio de Janeiro: Funarte, 1988.

VENEZIANO, Neyde, Não adianta chorar! Teatro de revista brasileiro... Oba!, Campinas, SP: Ed. UNICAMP, 1996.

, O teatro de revista no Brasil. Dramaturgia e convençôes, Campinas, SP: Editora da UNICAMP, 1991.

ZUMTHOR, Paul, A letra e a voz: a "literatura" medieval, São Paulo: Companhia das Letras, 1993. 


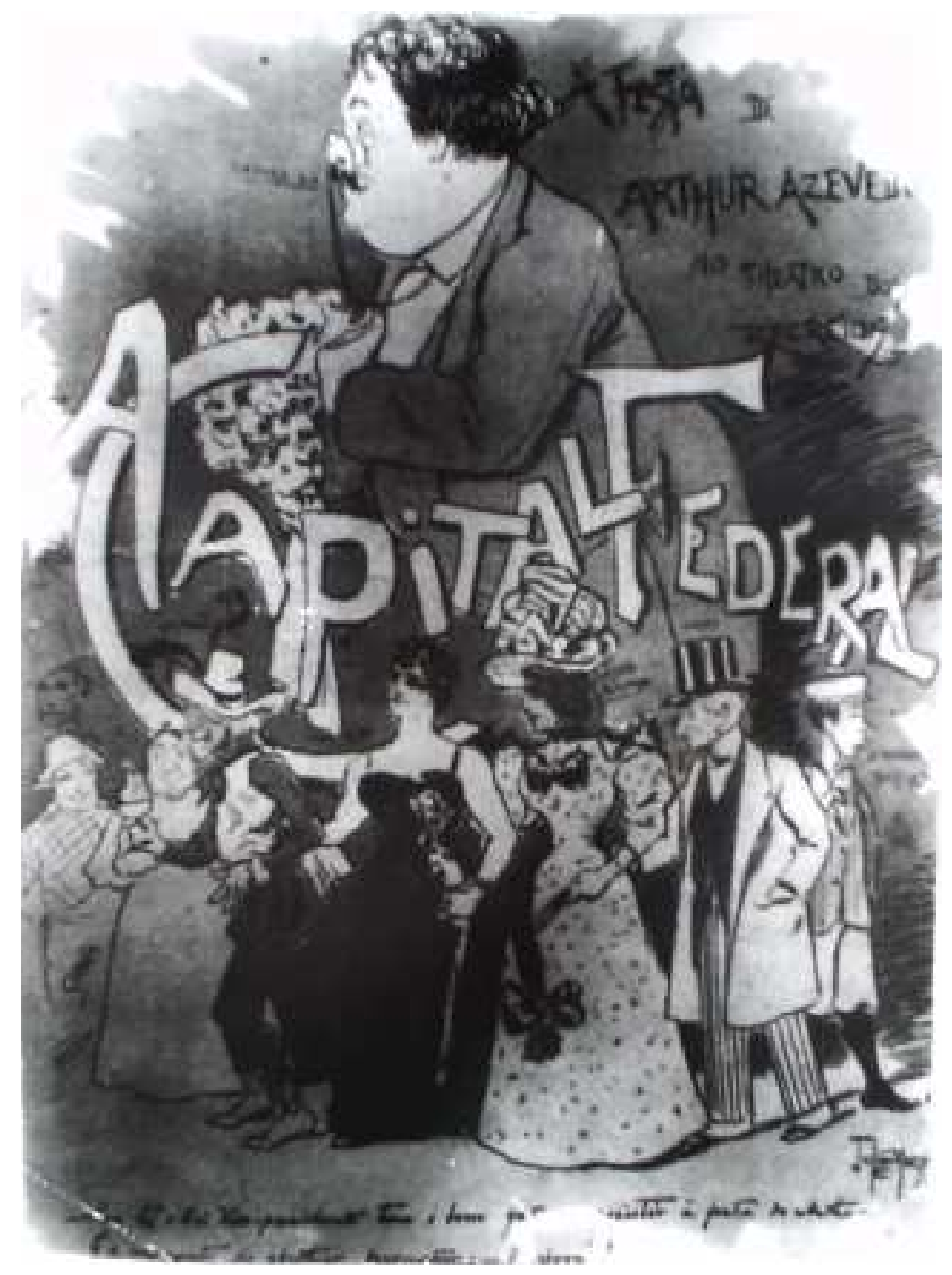

Fonte: “A Bruxa”, 26/02/1897 